\title{
Designing the Ares I Crew Launch Vehicle Upper Stage Element and Integrating the Stack at NASA's Marshall Space Flight Center
}

\author{
Garry Lyles, Associate Director for Technical Management \\ Neil E. Otte, Ares Chief Engineer \\ Engineering Directorate \\ NASA Marshall Space Flight Center \\ Huntsville, AL 35812
}

\begin{abstract}
Fielding an integrated launch vehicle system entails many challenges, not the least of which is the fact that it has been over 30 years since the United States has developed a human-rated vehicle - the venerable Space Shuttle. Over time, whole generations of rocket scientists have passed through the aerospace community without the opportunity to perform such exacting, demanding, and rewarding work. However, with almost 50 years of experience leading the design, development, and end-to-end systems engineering and integration of complex launch vehicles, NASA's Marshall Space Flight Center offers the in-house talent — both junior- and senior-level personnel - to shape a new national asset to meet the requirements for safe, reliable, and affordable space exploration solutions. ${ }^{1}$ These personnel are housed primarily in Marshall's Engineering Directorate and are matrixed into the programs and projects that reside at the rocket center. Fortunately, many Apollo era and Shuttle engineers, as well as those who gained valuable hands-on experience in the 1990s by conducting technology demonstrator projects such as the Delta-Clipper Experimental Advanced, X-33, X-34, and X-37, as well as the short-lived Orbital Space Plane, work closely with industry partners to advance the nation's strategic capability for human access to space. Currently, only three spacefaring nations have this distinction, including the United States, Russia, and, more recently, China. The U.S. National Space Policy of 2006 directs that NASA provide the means to travel to space, and the NASA Appropriations Act of 2005 provided the initial funding to begin in earnest to replace the Shuttle after the International Space Station construction is complete in $20100^{2}$ These and other strategic goals and objectives are documented in NASA's 2006 Strategic Plan. ${ }^{3}$

In 2005, a team of NASA aerospace experts conducted the Exploration Systems Architecture Study, which recommended a two-vehicle approach to America's next space transportation system for missions to the International Space Station in the next decade and to explore the Moon and establish an outpost around the 2020 timeframe. ${ }^{4}$ Based on this extensive study, NASA selected the Ares I crew launch vehicle configuration and the heavy-lift Ares V cargo launch vehicle (fig 1). This paper will give an overview of NASA's approach to integrating the Ares I vehicle stack using capabilities and assets that are resident in Marshall's Engineering Directorate, working in partnership with other NASA Centers and the U.S. aerospace industry. It also will provide top-level details on the progress of the in-house design of the Ares I vehicle's upper stage element.
\end{abstract}

\section{Vehicle Stack Integration}

The Ares I is an in-line rocket configuration, with a 5-segment reusable solid rocket booster first stage and an upper stage powered by a J-2X engine, capable of putting approximately 52,000 pounds into orbit. Next decade, the Orion crew exploration vehicle will first deliver crew and limited cargo to the International Space Station.

Toward the end of the next decade, the Orion and crew will rendezvous and dock with the Lunar Lander carried by the Ares V Earth departure stage. This combination will take astronauts to lunar orbit, where they will descend to the Moon in the Lunar Lander to explore 4 billion years of geological history and scout potential resources. Orion will await in orbit for the crew to return in the Lander's ascent stage; after transferring, they will return to Earth in Orion, for a landing on water or on Earth. This space transportation architecture leverages the knowledge and experience gained from tried-and-true systems such as the Saturn V and Shuttle, while leveraging modern design tools, manufacturing processes, operational concepts, and systems engineering standards and practices (fig. 2). 


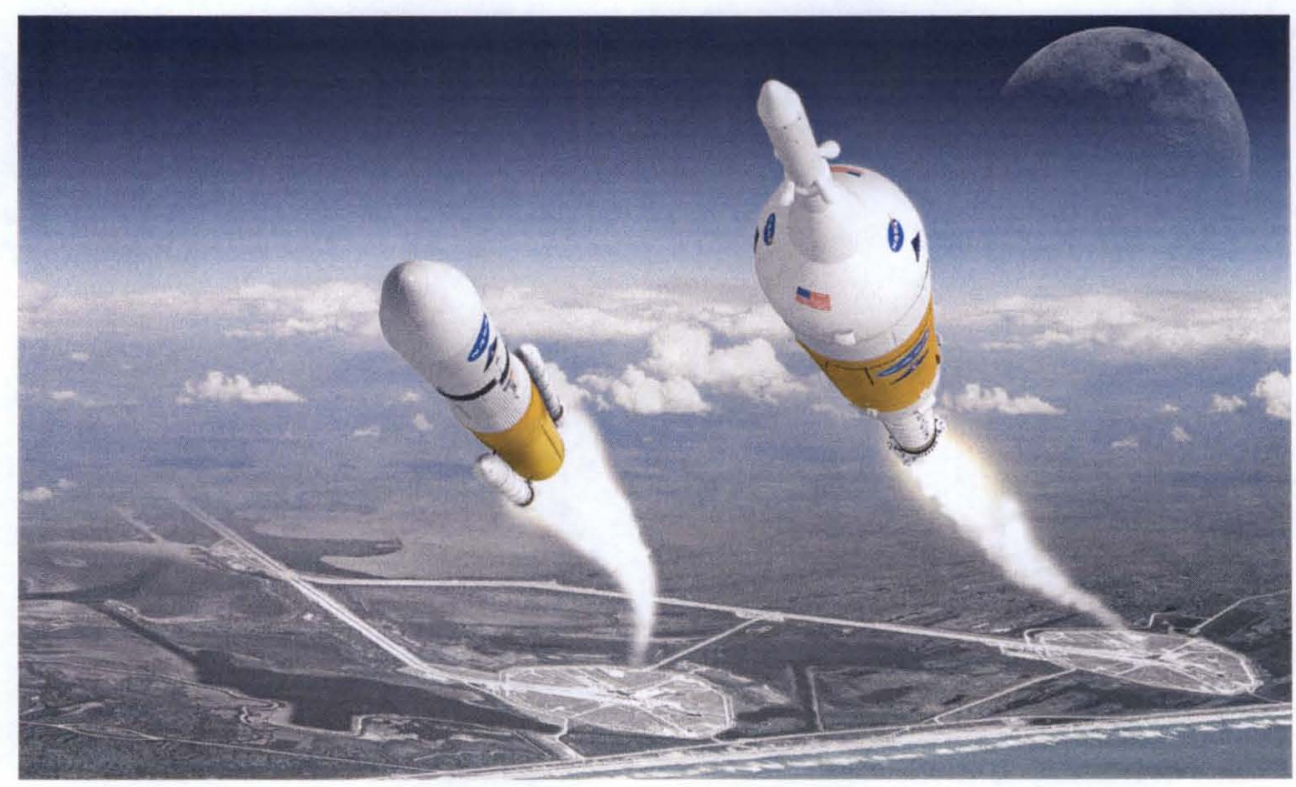

Fig. 1. NASA concept of America's new launch vehicles-Ares I (right) and Ares V.

The Constellation Program comprises multiple systems, including the Ares launch vehicles, Orion crew capsule, ground and mission operations, and the Lunar Lander and supporting infrastructure. Systems engineering and integration between and among these systems is being performed in house using rigorous standards codified in NASA's systems engineering regulation and in the Ares Projects Office's Systems Engineering Management Plan. NASA is committed to applying systems engineering and systems management processes and standards to ensure that technical performance is accurately reflected in, and inextricably connected to, budget allocations and schedule milestones. Systems engineering and integration is on par with the various hardware elements (first stage, upper stage, and upper stage engine), and includes functions such as requirements validation and management; subsystem design and integration; product development and validation (including testing); interface definition and control; and systems analysis (loads; thermal; guidance, navigation, and control; separation; and liftoff).

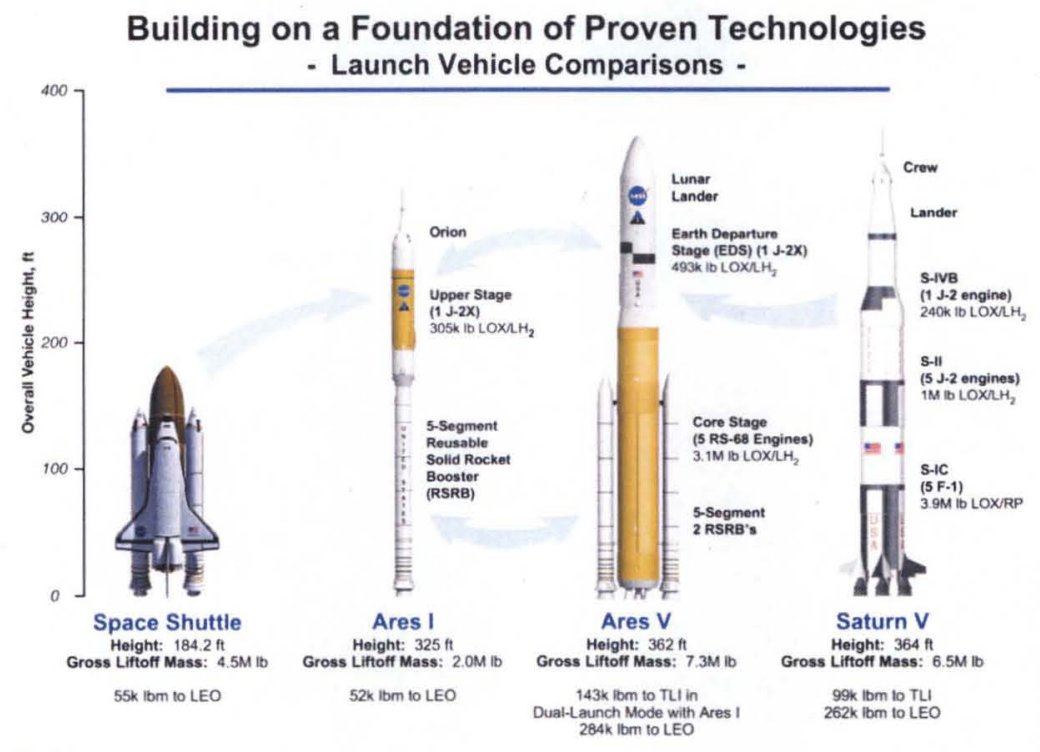

Fig. 2. The Ares I and Ares V are evolutionary space transportation solutions. 
The Ares I team consists of the range of engineering and business disciplines that come together formally and informally in working groups, integrated product teams, and governing councils and boards. In this way, decision-making is handled at the lowest possible level in most cases. As a testament to this systems engineering network, which includes the Chief Engineers and Safety and Mission Assurance representatives assigned to the project, in October 2007, the Ares team completed the second major milestone in the integrated vehicle's path to fielding — the System Definition Review - followed by an integrated vehicle technical interchange meeting, which uncovered several dynamic and weight challenges now being addressed by focus teams studying various options for resolution. The previous milestone - the System Requirements Review - was completed in November 2006. This review was focused on requirements validation and verification, and risk identification and mitigation, as well as baselining the reference vehicle design from which to continue systems engineering work.

The next major milestone - the Preliminary Design Review - will be conducted in 2008, followed by the initial suborbital test flight in April 2009, known as the Ares I-X mission (fig. 3), which will inform the next major milestone - the Critical Design Review - in late 2009. Flying the Ares I-X provides an early opportunity to perform proof-of-concept testing of the first stage's reusable solid rocket booster hardware, as well as to gather data about the dynamics of the integrated launch vehicle stack, including separation forces on the J-2X upper stage engine. In addition, as the Kennedy Space Center transitions from the Shuttle to the Ares/Orion system, the Ares I-X mission provides an excellent point from which to perfect ground operations scenarios, including modifications to Launch Complex 39B.

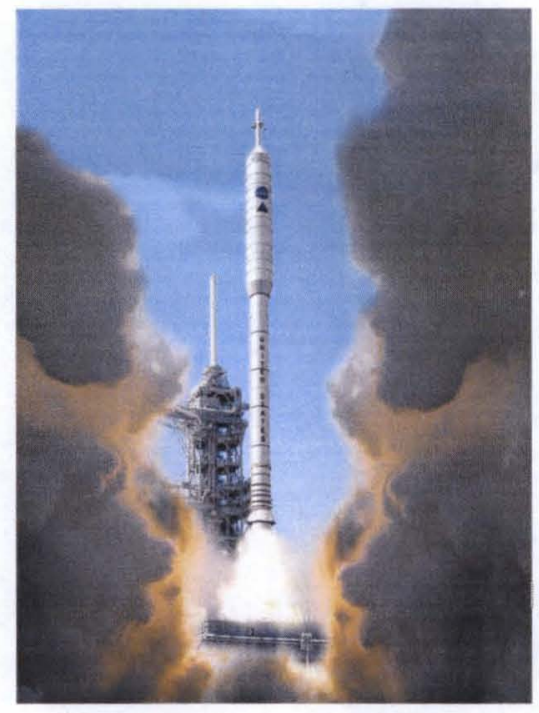

Fig. 3. Ares I-X mission concept.

Many Department of Defense and NASA projects alike support the Government serving in the lead systems integrator role to enhance mission success, especially in a multi-decade effort such as fielding America's new space transportation system. As stated in a recent article in NASA's Academy of Sharing Knowledge magazine: "A common misconception about systems engineering is that it is an up-front activity that takes place only in the requirements definition phase of a program or project life cycle. That view doesn't properly account for the complexity of engineering and integrating systems. As systems are added and modified over the course of development, the number and complexity of interfaces increases in a nonlinear fashion. Problems resulting from conflicting or missing interfaces are the norm, not the exception. The only way to deal with this type of dynamic environment is by adopting an end-to-end, logical systems approach that emphasizes robust modeling and simulation, verification, and validation testing. These rigorous systems processes must be repeated throughout the life cycle of a system to detect unexpected consequences that can flow from even small design changes." "7 These processes are informed by a portfolio of integrated vehicle testing, from scale models in wind tunnels, to major fullup ground vibration testing in Marshall's Dynamic Test Stand, to the series of developmental flight tests that will progress from remote-controlled flights, such as the Ares I-X mission discussed above, to those carrying crewmembers, prior to attaining initial operational capability. 
Systems engineering and integration builds and bridges communication channels between project management and technical implementation teams, and with in the various technical working groups where launch vehicle design, analysis, and testing are performed. It provides a framework for risk reduction and mission success built on the foundation of principles and practices that position hardware and software in a collaborative environment where government and contractor interests are united behind a common agenda.

\section{Upper Stage Design}

Whereas the ESAS suggested evolving proven technologies, for example the 5-segment reusable solid rocket booster, where possible, it also recommended a clean-sheet design upper stage powered by an upper stage engine such as the Space Shuttle Main Engine (SSME). Subsequent trade studies found that developing the J-2X engine for expendable use would be more cost effective than revamping the SSME for a throw-away application. In short, the upper stage is a new system, rather than a modification of an existing one. This approach allows engineers to fully incorporate state-of-the-art materials, processes, and hardware; adapt to vehicle configuration changes; standardize replacement parts; and build the upper stage to evolve with technological advances.

The Ares I upper stage is an aluminum-lithium alloy, self-supporting cylindrical structure that is 84 -feet long and 18 -feet in diameter. This second stage will provide the guidance, navigation, and control, while the J-2X upper stage engine will provide the thrust and propulsive impulse required for the second phase of the Ares I ascent flight after the first stage separates from the launch vehicle (fig. 4). The upper stage includes the main propulsion system, thrust vector control, avionics and software, reaction control system for roll and attitude control, and the separation system required to perform the first stage separation. It also holds the liquid oxygen/liquid hydrogen tanks for the J-2X engine operation. Most of the avionics will be housed in an instrument unit, which provides the mechanical and electrical interfaces between the Ares I and the Orion.

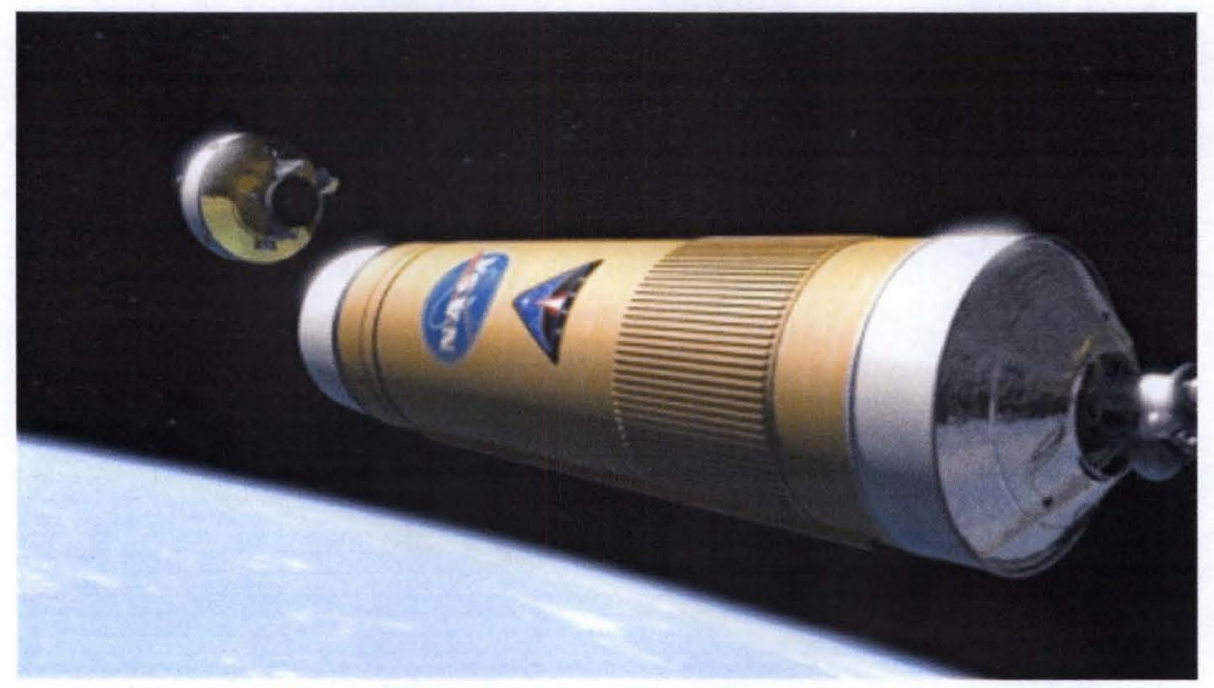

Fig. 4. A concept drawing of the Ares I upper stage, which will transport the Orion crew capsule to orbit.

The upper stage design and development team includes hundreds of civil servant and contract employees who provide support services, such as assembling one of the largest friction-stir welding machines to test materials and processes, as well as other members who create the designs, select the components, and conduct the tests to help make the second phase of the journey as safe, reliable, and cost-effective as possible. While an in-house team is designing the upper stage, it will be manufactured by the Boeing Company, which was selected in a competitive procurement process, using lean practices at NASA's Michoud Assembly Facility. This is a similar arrangement to the Saturn and Space Shuttle vehicles. Using NASA's design, Boeing is responsible for producing a ground test article, three flight test units, and six production flight units to support the flight manifest through 2016 . The production contract was awarded in August 2007. The upper stage element's System Definition Review was conducted in October 2007, and a variety of subsystem tests and a series of integrated main propulsion test article and ground vibration testing are being planned to validate computer modeling and simulation. The upper stage Preliminary Design Review is slated for 2008. 


\section{References}

1. NASA Constellation Architecture Requirements Document, CxP 00001, 2005.

2. U.S. National Space Policy, 2006, http://www.ostp.gov/

3. 2006 NASA Strategic Plan, NP-2006-02-423-HQ.

4. NASA Exploration Systems Architecture Study, Final Report, Technical Manual 2005-214062, November 2005, www.sti.nasa.gov

5. NASA Systems Engineering Processes and Requirements, NASA Procedure and Regulation 7123.1A, March 26, 2007.

6. Ares Projects Office Systems Engineering Management Plan, CxP 72018, Oct 4, 2006.

7. Stephen Kapurch, NASA Academy of Sharing Knowledge, Spring 2007, p. 37. 